\title{
Aetiological Factors and Foetomaternal Outcome in PROM
}

\author{
Swati Atrolia1 ${ }^{1}$, Shreya Chaitali Ekka², Sarita Tirkey³, Vinit Vivek ${ }^{4}$
}

${ }^{1}$ Department of Obstetrics and Gynaecology, Dumka Medical College, Jharkhand, India. ${ }^{2}$ Department of Obstetrics and Gynaecology, Hazaribagh Medical College, Hazaribagh, Jharkhand, India. ${ }^{3}$ Department of Obstetrics and Gynaecology, RIMS, Ranchi, Jharkhand, India. ${ }^{4}$ Department of Obstetrics and Gynaecology, Palamu Medical College, Jharkhand, India.

\section{ABSTRACT}

\section{BACKGROUND}

Premature rupture of membrane (PROM) refers to the disruption of foetal membranes before the beginning of labour, resulting in spontaneous leakage of amniotic fluid. Homeyr, GJ et al in his study "Amnio infusion for third trimester preterm rupture of membranes", march 2014 states that premature rupture of membranes (PROM), or pre-labour rupture of membranes, is a condition occurring in pregnancy and defined it as rupture of membranes (breakage of the amniotic sac), commonly called breaking of the mother's water (s), more than one hour before the onset of labour.

\section{METHODS}

The present study was carried out in the Department of Obstetrics and Gynaecology of Rajendra Institute of Medical Sciences (RIMS), Ranchi, during from April 2017 to October 2018. A total 595 cases were studied. The cases were divided into two groups, Study Group-195 cases and Control Group- 400 cases.

\section{RESULTS}

Various factors were studied and analysed. Incidence of PROM in the present study was $7.49 \%$. Out of 195 cases $68 \%$ were term PROM and 32\% were preterm PROM. Mean age in the study group was 23 yrs. Risk factors associated with PROM in most of the cases was unknown (52\%). Other causes were anaemia 34\%, cervicovaginal infections $16 \%$, malpresentation $10 \%$, multiple gestation $3.5 \%$, prior cervical surgery $1 \%$, history of fall $1 \%$ PROM following coitus was $1.5 \%$. In the present study the correlation between CRP and clinical chorioamnionitis was significant. Caesarean section was done was done in $19 \%$ cases in study group. There were $3 \%$ cases of chorioamnionitis in study group. Out of 10 patients in the study group, maximum patients had puerperal sepsis (4 patients- $40 \%$ ) followed by UTI $(30 \%)$, wound infection (20\%) and breast engorgement (10\%).

\section{CONCLUSIONS}

Premature infant puts immense burden on the economy and health care resources of the country. Therefore, management of PPROM requires accurate diagnosis and evaluation of the risks and benefits of continued pregnancy or expeditious delivery. Once PROM is diagnosed, it is important to weigh the risk of PROM and prematurity and make the right choice for conservative management or active interventions. Adequate antenatal care should be advocated so that appropriate risk assessment can be done, and intervention provided where applicable. Neonatal units should also be equipped to be able to render necessary care for these preterm neonates thereby reducing the morbidity and mortality associated with PPROM.

\section{KEY WORDS}

PROM, PPROM, Aetiological Factors, Foetomaternal Outcome, Cervicovaginal Infections, CRP, ESR, Vaginal Swab
Corresponding Author:

Dr. Swati Atrolia,

Department of Obstetrics and Gynaecology, Dumka Medical College,

Jharkhand, India.

E-mail: swati20angel@gmail.com

DOI: $10.14260 /$ jemds/2020/20

Financial or Other Competing Interests: None.

How to Cite This Article:

Atrolia S, Ekka SC, Tirkey S, et al. Aetiological factors and foetomaternal outcome in PROM. J. Evolution Med. Dent. Sci. 2020;9(02):91-96, DOI: $10.14260 / \mathrm{jemds} / 2020 / 20$

Submission 10-09-2019,

Peer Review 25-12-2019,

Acceptance 01-01-2020,

Published 13-01-2020. 


\section{BACKGROUND}

Prematurity being a very important complication of PROM with subsequent perinatal mortality and morbidity and maternal morbidity, this topic PROM was chosen for the study, so as to evaluate the condition of PROM with timely detection, early investigation, management and proper treatment to reduce perinatal morbidity and mortality mainly due to prematurity and infection and also to reduce the maternal morbidity by preventing infection. Premature rupture of membrane (PROM) ${ }^{1}$ refers to the disruption of foetal membranes before the beginning of labour, resulting in spontaneous leakage of amniotic fluid. ${ }^{2}$ Homeyr, GJ et al in his study "Amnio infusion for third trimester preterm rupture of membranes", march 2014 states that -Premature rupture of membranes (PROM), or pre-labour rupture of membranes, is a condition occurring in pregnancy and defined it as rupture of membranes (breakage of the amniotic sac), commonly called breaking of the mother's water (s), more than one hour before the onset of labour. ${ }^{3}$ The sac (Consisting of two membranes: the chorion and amnion) contains amniotic fluid, which surrounds and protects the foetus in the uterus (Womb). After rupture, the amniotic fluid leaks out of the uterus, through the vagina. Planned home versus hospital care for preterm prelabour rupture of the membrane prior to 37 wks.", April 2014 states - If PROM occurs before 37 weeks, it is called preterm premature rupture of membranes (PPROM) and the foetus and mother are at greater risk for complications. PPROM causes one-third of all preterm births ${ }^{4}$ and babies born preterm (before 37 weeks) can suffer from the complications of prematurity, including death.

PROM occurs in approximately $5 \%-10 \%$ of all pregnancies, of which approximately $8 \%$ occur at term. The three causes of foetal death associated with PROM are sepsis, asphyxia, and pulmonary hyperplasia. PROM is linked to significant maternal and foetal morbidity and mortality. It has been shown to be the cause of $18 \%-20 \%$ and $21.4 \%$ of perinatal mortalities and perinatal morbidity respectively. 5,6 Bond et al, March 2017 states -Most women will experience a painless leakage of fluid out of the vagina. They may notice either a distinct "Gush" or a steady flow of small amounts of watery fluid in the absence of steady uterine contractions. ${ }^{7}$ Loss of fluid may be associated with the foetus becoming easier to feel through the belly (due to the loss of the surrounding fluid), decreased uterine size, or meconium (foetal stool) seen in the fluid. ${ }^{8}$ Birth following spontaneous preterm labour and spontaneous preterm of the membranes (PPROM) together called spontaneous preterm birth are considered a syndrome caused by multiple aetiologies, including infection/inflammation, vascular disease, uterine over distension and immunological disorders. ${ }^{5}$ The aetiology of pprom is multifactorial. The exact cause of rupture of membranes is obscure, but various factors have been attributed as aetiological factors e.g. infection, increased amniotic pressure, cervical incompetence, multiple pregnancy, increased maternal age, parity, poor nutritional factors and foetal factors like position presentation and lie.

Maternal complications include intra-amniotic infection, which occurs in $13 \%-60 \%$ of women with PROM, placental abruption, and postpartum endometritis. ${ }^{9,10}$ Pre-term birth, infection, hypertensive disease, and asphyxia are cited as the most common contributors to maternal and foetal mortality in developing countries.11,12 Evidence suggests that the rupture of membrane is related to infection, ${ }^{13}$ membrane dysfunction on a molecular level, ${ }^{14}$ collagen destruction and programmed cell death in foetal membranes. ${ }^{15,16}$ The complication risk of PROM is increased if the mother has previous PROM, low body mass index, concomitant infection of the gestational tissues, and longer the time elapsed between the rupture and delivery. ${ }^{17}$ PROM has essential significance for the further fate of pregnancy. Late diagnosis means wasted opportunity of appropriate intervention. In most cases, the diagnosis does not cause bigger problems, but in some situations, it may not be easy to make the right diagnosis. Preterm premature rupture of the membranes (PPROM) is responsible for one third of all preterm births. Subclinical intrauterine infection has been implicated as a major aetiological factor in the pathogenesis and subsequent maternal and neonatal morbidity associated with PPROM.

Preterm delivery is a worldwide public health problem and it occurs in approximately $6-12 \%$ of all pregnancies. Preterm prelabour rupture of membranes is defined as amniotic fluid leakage after $28 \mathrm{wk}$., and before $36+6 \mathrm{wk}$., of gestation and it represents approximately $30-40 \%$ of all preterm deliveries. (Coelette Kanellopoulos Langeni et al, Oct 2015). The presence of microorganisms activates inflammatory response in amniotic cavity in such cases and it is associated with early preterm delivery.

\section{Objective}

As prematurity being a very important complication of PROM with subsequent perinatal mortality and morbidity and maternal morbidity, this topic PROM was chosen for study so as to evaluate the condition of PROM. PROM is linked to significant maternal and foetal morbidity and mortality. It has been shown to be the cause of $18 \%-20 \%$ and $21.4 \%$ of perinatal mortalities and perinatal morbidity respectively. The present study was undertaken to study the aetiological factors and to evaluate the foetomaternal outcome following prelabour rupture of membranes after 28 weeks of gestation and was compared to that of normal pregnancy.

\section{METHODS}

The cases for the study were selected from those patients who were admitted in Professor Dr. Sarita Tirkey unit in labour room emergency, Department of Obstetrics and Gynaecology. A total 595 cases were studied. The cases were divided into two groups viz- Study Group-195 cases; The cases were the ones in whom the membranes ruptured after 28 wks., of gestation but before the onset of labour pains and Control Group- 400 cases; Control group consisted of 400 patients going to labour with intact membranes. As there were 400 normal cases during period of study control is taken to be as. It is a prospective study.

Inclusion criteria included pregnant women with complains of leaking per vaginum after 28 weeks of gestation i.e. both PPROM (i.e. PROM after 28 weeks and before 37 weeks) and term PROM (i.e. PROM at and after 37 completed weeks). Both primigravida and multigravida were included in the study. Exclusion criteria comprised Pregnant women withGestational age less than 28 wks., Antepartum haemorrhage, 
Preeclampsia and eclampsia, known medical disorders like diabetes mellitus and heat disease. To diagnose microbial invasion of amniotic cavity (MIAC) antenatally involves invasive procedure like amniocentesis. Culture of amniotic fluid is most reliable test but is of limited utility since culture results may not be available for 3 days. In addition, because of invasive nature of amniocentesis it is not performed in majority of cases. Therefore, noninvasive approaches were widely proposed e.g. maternal serum $\mathrm{C}$ reactive protein (CRP), blood count, vaginal swab cultures. Antenatal diagnosis of chorioamnionitis is important for early treatment and prevention of foetomaternal complications

In all cases with history of prelabour rupture of membranes, after confirming the diagnosis, inj. ampicillin (2 gm I.V. qid) was given routinely to prevent infection. In those cases where duration of gestation was less than 34 wks., 2 doses of I.M. betamethasone $12 \mathrm{mg}$ were given at 12 hourly intervals to accelerate foetal lung maturity. If pregnant woman with preterm PROM was having uterine contractions at admission, then oral nifedipine was given as tocolytic at least for $48 \mathrm{hrs}$ to have the benefit of glucocorticoid administration.

Management depended on the gestational age and whether the pregnant women was in labour or not. If she was not in labour and there was no evidence of infection or foetal distress, she was observed carefully, generally spontaneous labour ensued within $24 \mathrm{hrs}$.

If labour did not start within stipulated time or if it was term, then induction of labour was done after bishop's score and pelvic assessment. If the pelvis was adequate and bishop scoring was unfavourable then cervical ripening was done with PGE2 gel in posterior fornix 6 hrly. Then inj. oxytocin was used if needed to expedite the delivery. Amnioinfusion was done if the liquor was very scanty or was thick meconium stained. Caesarean section was performed for obstetric indication or failed induction. Active management of third stage of labour was done. Maternal assessment was done by recording pulse, blood pressure, temperature and respiration, lochia.

\section{Statistical Analysis}

Total 595 cases were studied to observe "Aetiological Factors and Foetomaternal Outcome in PROM". 400 cases of normal pregnancy were taken as control and 195 cases were taken as study group. Total number of deliveries during the period of work were 2601. Out of them, 195 cases had prelabour rupture of membranes. So, incidence of PROM turns out to be 7.49\%. Preterm PROM-2.4\% and Term PROM-5.04\%. [Fig. 1]

\section{RESULTS}

In study group, the mean age (mean \pm S.D.) of patients was $23.7641 \pm 3.0181$ years. In control group, the mean age (mean \pm S.D.) of patients was $24.8700 \pm 3.2619$ years. Difference of mean age in both the groups was statistically significant $(p=0.0001)$. [Table 1] and Difference of mean gestational age in both the groups was statistically significant ( $p<0.0001)$. [Table 2]. Out of 195 cases of study group, 68 patients (34\%) had anaemia and out of 400 patients in control group 105 cases (26\%) had anaemia. Out of 195 cases in study group 31 patients $(16 \%)$ had cervicovaginal infection and out of 400 cases in control group, 20 cases (5\%) had cervicovaginal infection. Out of 195 cases in study group 20 patients had malpresentation (3.5\%) and 5 cases $(1.2 \%)$ had malpresentation in the 400 cases of control group. Out of 195 cases 7 patients (3.5\%) had multiple gestation and in 400 controls, 2 patients $(0.5 \%)$ had multiple gestation. 2 patients $(1 \%)$ in 195 cases had history of fall whereas there was no history of fall in among control group. 2 patients (2\%) had history of cervical surgery in study group. 1.5\% (3 patients) had history of preterm. In maximum no of patients (52\%- 102 patients) the cause for PROM was unknown. [Table 3]
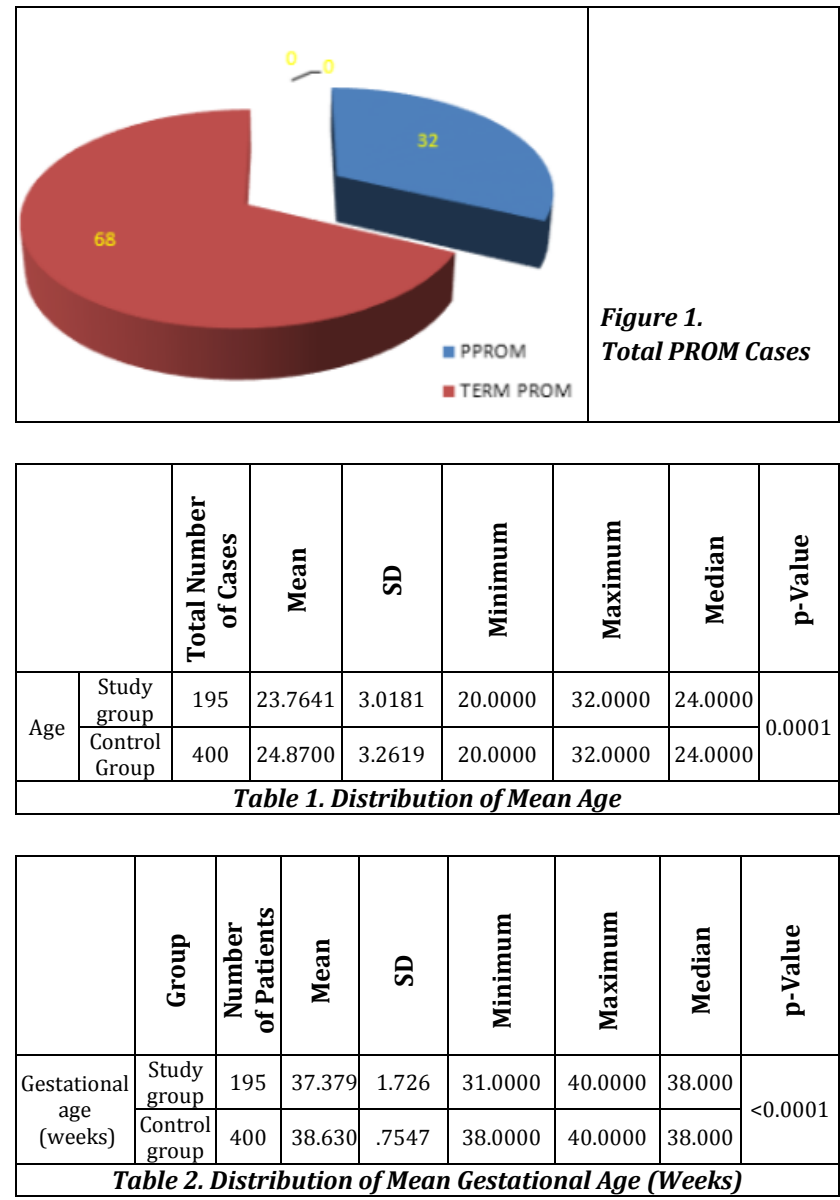

\begin{tabular}{|c|c|c|c|}
\hline Aetiological Factors & $\begin{array}{c}\text { Study Group } \\
\text { (Total 195 Cases) }\end{array}$ & $\begin{array}{c}\text { Control Group } \\
\text { (Total 400 Cases) }\end{array}$ & Total \\
\hline Anaemia & $68(34 \%)$ & $105(26 \%)$ & 173 \\
\hline $\begin{array}{c}\text { Cervicovaginal } \\
\text { Infections }\end{array}$ & $31(16 \%)$ & $20(5 \%)$ & 51 \\
\hline Malpresentation & $20(10 \%)$ & $5(1.2 \%)$ & 25 \\
\hline Multiple Gestation & $7(3.5 \%)$ & $2(0.5 \%)$ & 9 \\
\hline History of Fall & $2(1 \%)$ & 0 & 2 \\
\hline History of Coitus & $3(1.5 \%)$ & 0 & 3 \\
\hline Smoking & 0 & 0 & 0 \\
\hline Prior Cervical Surgery & $2(1 \%)$ & 0 & 0 \\
\hline $\begin{array}{c}\text { Prior History of Preterm } \\
\text { Labour }\end{array}$ & $3(1.5 \%$ & 0 & 0 \\
\hline Table 3. Aetiological Factors in the Study and the Control Groups \\
\hline
\end{tabular}

Difference of mean pulse rate, mean Neutrophil, mean Lymphocytes, mean Basophil, mean ESR, mean Monocytes and mean Eosinophil in both the groups was not statistically significant. Association between High Vaginal Swab in case and control group was statistically significant. Out of 195 patients in study group, 52 patients $(27 \%)$ went in spontaneous labour and induction of labour was done with Cerviprime gel (Prostaglandin E2) in 143 patients (73\%). Induction of labour 
was done in patients with term pregnancy and in those who had signs of infection. In study group (195 patients), 16\% (6 patients) had caesarean for failed induction and $24 \%$ (9 patients) had caesarean for foetal distress. The most common indication of caesarean was malpresentation (52\%- 20 pts), followed by foetal distress (24\%- 9 pts), failed induction (16\%- 6 pts), others (8\%- 3 pts). This was statistically significant. Out of 10 patients in study group maximum patients had puerperal sepsis (4 patients- $40 \%$ ) followed by UTI $(30 \%)$, wound infection (20\%)and breast engorgement (10\%), Whereas in control group (total 5 cases) maximum no. of patients had UTI (40\%) followed by puerperal sepsis, wound infection, and breast engorgement which had equal incidence (10\%).

In study group, 6 (3.1\%) patients had chorioamnionitis. In control group, all patients had no chorioamnionitis. Association of chorioamnionitis in both the groups was statistically significant ( $\mathrm{p}=0.0004) .13$ pts., were between 2834 wks., out of which 8 patients $(61 \%)$ patients went into spontaneous labour in less than $24 \mathrm{hrs}$. whereas 49 patients were between gestational age of $\geq 34 \mathrm{wk}$., and less than 37 weeks out of which 44 patients (90\%) went into spontaneous labour within $24 \mathrm{hrs}$. This was statistically significant. In study group 193 (95\%) neonates had live birth. In control group, 401 $(99.75 \%)$ neonates had live birth. Association of neonatal outcome in both the groups was statistically significant ( $\mathrm{p}=0.0001)$. In the study group 7\% (15 neonates) had weight less than $1.5 \mathrm{~kg}$ and $40 \%$ (80 neonates) had weight more than $2.5 \mathrm{~kg}$ whereas in control group $2 \%$ (8 neonates) had weight less than $1.5 \mathrm{Kg}$ and $60 \%$ (240 neonates) had weight more than $2.5 \mathrm{~kg}$ (this was clinically significant). All the $7 \%(15$ patients) were less than 37 wks. with PROM who had neonatal morality.

In study group, 27 (13.8\%) patients had birth asphyxia. In control, $8(2.0 \%)$ patients had birth asphyxia. Association of birth asphyxia in both the group was statistically significant ( $p<0.0001)$. In study group, $19(9.7 \%)$ patients had sepsis. In control group, $2(0.5 \%)$ patients had no sepsis. Association of sepsis in both the groups was statistically significant $(\mathrm{p}<0.0001)$.

\section{DISCUSSION}

Total number of deliveries during the study period was 2601 out of which 195 cases were of prelabour rupture of membranes. So, the incidence of PROM was $7.49 \%$. This was similar to Bhalerao and Desai (2003). ${ }^{18}$ Bhide $^{19}$ (2001) who reported an incidence of PROM between $7-12 \%$. We found that in our study, the mean age (mean \pm S.D.) of patients in study group was $23.7641 \pm 3.0181$ years. In control group, the mean age (mean \pm S.D.) of patients was $24.8700 \pm 3.2619$ years. Difference of mean age in both the groups was statistically significant $(\mathrm{p}=0.0001)$. The possible explanation could be that 20-30 years is the peak reproductive age group and early marriage in India.

In the present study aetiological factor in most of the patients was unknown followed by anaemia (57.7\%- 56 patients), cervicovaginal infections (16\%, 31 patients), malpresentation (10\%, 20 patients), multiple gestation (3.5\%, 7 patients), history of coitus (1.5 \%, 3 patients), history of fall
(1\%, 2 patients) and prior cervical surgery (1\%, 2 patients) The results were similar to the study of Choudhary et al, Oct2015 in which aetiological factors were unknown in most of the cases. $32 \%$ patients in study group and $9 \%$ patients in control group had anaemia, 18\% patients in study group and $6.5 \%$ in control group had genitourinary infection. Amirabi et al, May 2012 found that sensitivity and specificity of a positive ESR at a cutoff value 52 pts were $66.7 \%$ and $60 \%$ respectively. The findings of the study were not supportive of using WBC count as a reliable diagnostic test to identify chorioamnionitis in PROM but ESR diagnostic value was minimally acceptable whereas in the present study ESR was not statistically significant.

We found that in case, 6 (3.1\%) patients had chorioamnionitis. In control, all patients had no chorioamnionitis. Association of chorioamnionitis both the group was statistically significant $(\mathrm{p}=0.0004)$. In study group, 10 (5.1\%) patients had Puerperal fever. In control, 9 (2.3\%) patients had no Puerperal fever. Association of Puerperal fever vs. group was not statistically significant $(p=0.0608)$. Rana $M$ found that the most common complication was clinical chorioamnionitis (6\%) and postpartum sepsis (6\%). Ivana Musilova et al, Aug, 2017, found that women with microbial invasion of amniotic cavity (MIAC) and intra amniotic invasion (IAI) had high maternal CRP concentration than did women without (with MIAC: median $6.9 \mathrm{mg} / \mathrm{L}$ vs. without MIAC: median $4.9 \mathrm{mg} / \mathrm{L}, \mathrm{p}=0.02$; with $\mathrm{IAI}$; median $8.6 \mathrm{mg} / \mathrm{L}$ vs. without IAI: median $4.7 \mathrm{mg} / \mathrm{L} ; \mathrm{p}<0.0001)$. Women with presence of both MIAC and IAI had high maternal CRP than with women with IAI and MIAC alone.

The maternal serum CRP cut-off value of $17.5 \mathrm{mg} / \mathrm{L}$ was best to identify both MIAC and IAI with sensitivity of $47 \%$, specificity $96 \%$, positive predictive value of $42 \%$, negative predictive value $96 \%$ and negative likelihood ratio of 10.9. In the present study the correlation between CRP and clinical chorioamnionitis was significant. This was similar to study "the significance of CRP in women with premature rupture of membranes", Ismail MA et $\mathrm{al}^{20}$ which states that when CRP values were normal, clinical chorioamnionitis was rarely found, whereas pathologically diagnosed chorioamnionitis was found half of the time. According to Trochez-Martinez et $\mathrm{al}^{21}$ RCOG, 2007, Although there is an association between an elevated CRP level and histological chorioamnionitis, the use of commonly accepted CR levels can be misleading. If single measurements are to be used, it would seem appropriate to consider higher cut-off levels of at least $30 \mathrm{mg} / \mathrm{L}$. For serial $\mathrm{CRP}$, levels of $20 \mathrm{mg} / \mathrm{L}$ or above seems predictive of infection.

Association of high vaginal swab in both groups was statistically significant $(\mathrm{p}<0.0001)$. El Taher F.T. et al ${ }^{22}$ June 2004 found in their study that infection was most common factor associated with PROM. The data indicated that $50 \%$ of patients had positive results of infection and other $50 \%$ had no infection. GBS group B streptococcus was the most common microorganism isolated from lower genital tract by high vaginal swab $61 \%$, followed by candida albicans $5 \%$ and trichomonas vaginalis $5 \%$. Pradeep Shivaraju et al, ${ }^{23}$ IJRCOG, 2015 found in their study that out of 80 high vaginal swab 40 patients had growth and 40 were sterile coagulase negative staphylococcus aureus were the commonest isolated organism followed by candida.

13 pts., were between 28-34 wks., out of which 8 patients (61\%) patients went into spontaneous labour in more than 24 
hrs. whereas 49 patients were between gestational age of greater $34 \mathrm{wk}$., and less than 37 weeks out of which 44 patients (90\%) went into spontaneous labour within $24 \mathrm{hrs}$. this was statistically significant This was similar to the study done by Rana $\mathrm{M}$ et $\mathrm{al}^{24}$, according to which the rate of spontaneous labour increased as the gestational age at admission increased. The rate of spontaneous labour was $67 \%$ at $28-32$ wks and $86 \%$ at $34-36$ wks. Shukla $\mathrm{P}$ et $\mathrm{al}^{25}$ found that $26.5 \%$ cases were PPROM remote from term and $73.5 \%$ cases were PPROM near term. Out of 200 PPROM cases, 171 delivered vaginally and 29 delivered by LSCS. Pradeep Shivaraju et al., Aug. 2015, found that out of 68 patients $77.9 \%$ delivered by vaginal delivery and $22 \%$ delivered by caesarean.

According to baby live/still birth in case, 186 (95.4\%) patients had live birth. According to baby live/still birth in control, 399 (99.8\%) patients had live birth. Association of baby live/still birth vs. group was statistically significant $(\mathrm{p}=0.0001)$. It was found that in study group, $19(9.7 \%)$ neonates had sepsis. In control group, $2(0.5 \%)$ patients had sepsis. Association of Okunades KS et $\mathrm{al}^{26}$ found that the mean gestational age at delivery was $32.7 \pm 2.4$ weeks. Caesarean section was the mode of delivery in $49.3 \%$ of cases, $8.1 \%$ of the women had clinical evidence of chorioamnionitis, $4.9 \%$ had puerperal sepsis while 1 maternal death was recorded. Ninety four percent (94\%) of the births were live births while $6 \%$ were stillbirths. Low birth weight was noted in $79.1 \%$ and birth asphyxia was observed in 7.4\%. Neonatal Unit admission was necessary in $72.5 \%$ of the live births. Perinatal mortality in this study was $17 \%$. PPROM is an important cause of adverse foetomaternal outcome with increased perinatal and maternal morbidity and mortality. In the study, 22 (11.3\%) patients had neonatal mortality. In control, $1(0.3 \%)$ patients had no neonatal mortality. Association of neonatal mortality vs. group was statistically significant $(\mathrm{p}<0.0001)$.

Palve TT et $\mathrm{al}^{27}$ found that maximum cases were in the age group of 20-25 years (55\%). Most cases presented at 37-40 weeks' gestation (68.3\%)and were primigravida (51.7\%). $18.3 \%$ cases were of preterm PROM. $73.3 \%$ patients delivered vaginally. $18.3 \%$ cases were delivered by LSCS without trial of labour, the commonest indication of which was malpresentation (36.2\%). 68.3\% cases had a third trimester USG s/o AFI $>10 \mathrm{cms} .10 \%$ had a third trimester USG s/o AFI < $5 \mathrm{~cm}$ (Lowest AFI = $1 \mathrm{~cm}$ ). Of these, 4 delivered by LSCS without trial of labour (commonest indication: severe Oligo/IUGR) and 2 delivered vaginally. 8.3\% cases delivered by LSCS after being given a trial of labour. The commonest indication of LSCS after trial of labour was foetal distress (60\%). Majority of the babies had a birth weight ranging from $2.5-3 \mathrm{Kg}(50 \%)$. Out of 60,16 neonates required NICU admission (26.7\%), commonest indication being Respiratory distress ( 7 out of 16 cases). 5 out of 16 NICU admissions were for Low birth weight $(<1.8 \mathrm{Kg})$. Maternal complications seen were fever (10\%), wound gape $(3.33 \%)$ and anaemia, requiring blood transfusion $(3.33 \%)$. PROM is associated with poor foetomaternal outcome which can be prevented by early diagnosis and prompt management.

Shukla P et al ${ }^{25}$ Out of 200 PPROM cases 171 delivered vaginally and 29 delivered by LSCS. Maternal morbidity was observed in 33 cases. In this study $95 \%$ live birth and 5\% were still birth. RDS was the commonest neonatal morbidities $32 \%$ followed by neonatal sepsis $20.0 \%$.

\section{CONCLUSIONS}

Antenatal care is an important tool to prevent PPROM by identifying the risk factors and its management. Steroid for foetal lung maturity, antibiotics to prevent foetal and maternal infection and induction and/or augmentation of labour will speed the delivery and reduce hospital stay and infection. Management of PPROM requires accurate diagnosis and evaluation of the risks and benefits of continued pregnancy or expeditious delivery. Once PROM is diagnosed, it is important to weigh the risk of PROM and prematurity and make the right choice for conservative management or active interventions. Proper antenatal monitoring, minimal vaginal examination under strict aseptic precautions, screening of lower genital tract infections and its adequate treatment are important measures to prevent PROM and improve maternal morbidity and neonatal morbidity and mortality. Adequate antenatal care should be advocated so that appropriate risk assessment can be done, and intervention provided where applicable. Neonatal units should also be equipped to be able to render necessary care for these preterm neonates thereby reducing the morbidity and mortality associated with PPROM.

\section{REFERENCES}

[1] Norwitz ER, Arulkumaran S, Symonds I, et al. Oxford American Handbook of Obstetrics and Gynecology. 1 $1^{\text {st }}$ edn. USA: Oxford University Press 2007: p. 268.

[2] Committee on Practice Bulletins-Obstetrics. ACOG Practice Bulletin No. 188: prelabour rupture of membranes. Obstetrics and Gynecology 2018;131 (1):e1e14.

[3] Hofmeyr GJ, Eke AC, Lawrie TA. Amnioinfusion for third trimester preterm premature rupture of membranes. Cochrane Database of Systematic Reviews 2014; (3):CD000942.

[4] El Senoun GA, Dowswell T, Mousa HA. Planned home versus hospital care for preterm prelabour rupture of the membranes (PPROM) prior to 37 weeks' gestation. The Cochrane Database of Systematic Reviews 2014; (4):CD008053.

[5] Shyam VD, Parikshit T, Ho PC, et al. Handbook on Preterm prelabour rupture of membranes in a low resource setting. $1^{\text {st }}$ edn. JP Brothers Medical Publisher 2012.

[6] Keeling JW. foetal and neonatal pathology. Springer Science \& Business Media 2013: p. 325.

[7] Bond DM, Middleton P, Levett KM, et al. Planned early birth versus expectant management for women with preterm prelabour rupture of membranes prior to 37 weeks' gestation for improving pregnancy outcome. The Cochrane Database of Systematic Reviews 2017; (3):CD004735.

[8] Vergani P, Locatelli A, Verderio M, Premature rupture of the membranes at $<26$ weeks' gestation: role of amnioinfusion in the management of oligohydramnios. Acta Biomedica: Atenei Parmensis 2004;75 Suppl 1:62-6.

[9] Mercer BM. Preterm premature rupture of the membranes. The Global Library of Women's Medicine 2009. doi:10.3843/GLOWM.10120. 
[10] Charles B. Obstetrics and Gynecology. Premature rupture of membranes. Chapter -22 . $6^{\text {th }}$ edn. Baltimore, MD: Lippincott Williams \& Wilkins 2010: p. 213-16.

[11] DeCherney A. Current diagnosis \& treatment: obstetrics \& gynecology. Chapter - 14. Late pregnancy complication, section: premature rupture of membranes. New York: McGraw-Hill Medical Publisher 2013.

[12] Cunningham F. Williams Obstetrics. Chapter - 23. Abnormal labour. New York: McGraw-Hill Education 2014.

[13] Charles B. Obstetrics and Gynecology. Chapter - 17. Premature rupture of membranes. $7^{\text {th }}$ edn. Philadelphia: Wolters \& Kluwer Health/Lippincott Williams \& Wilkins 2014: p. 169-73.

[14] Catherine S. Williams Obstetrics. Chapter - 22. Normal labour. New York: McGraw-Hill Medical Publication 2018.

[15] Sharp GC, Stock SJ, Norman JE. foetal assessment methods for improving neonatal and maternal outcomes in preterm prelabour rupture of membranes. The Cochrane Database of Systematic Reviews 2014;1 (0):CD010209.

[16] Bacterial Sepsis in Pregnancy. Royal College of Obstetricians and Gynaecologists. Green-top Guideline. No. 64a: April 2012.

[17] Wojcieszek AM, Stock OM, Flenady V. Antibiotics for prelabour rupture of membranes at or near term. The Cochrane Database of Systematic Reviews 2014; (10):CD001807.

[18] Bhalero S, Desai A. Premature rupture of membranes. In: Saraiya UB, Rao KB, Chatterji A, eds. Principles and practice of obstetrics and gynaecology. 2nd edn. A FOGSI Publication New Delhi: Jaypee Brothers 2003: p. 125.
[19] Bhide AG. Pregnancy at risk: concepts. In: Krishna UR, Tank DK, Daftry SN, eds. Premature rupture of membranes 4th edn. New Delhi: A FOGSI Publication, Jaypee Brothers 2001.

[20] Ismail MA, Zinaman MJ, Lowensohn RI, et al. The significance of $\mathrm{C}$ - reactive protein levels in women with premature rupture of membranes. Am J Obstet Gynecol 1985;151 (4):541-4.

[21] Trochez-Martinez RD, Smith P, Lamont RF. Use of Creactive proteins as a predictor of choriamnionitis in preterm prelabour rupture of membranes: a systematic review. BJOG 2007;114 (7):796-801.

[22] El Taher FT, Afifi NM, Khadija AH, et al. C-reactive proteins in the premature rupture of membranes. Qatar Medical Journal 2004;13 (1):19-23.

[23] Shivaraju P, Purra P, Bheemagani N, et al. Vaginal infections and its relation to preterm labour, PPROM, PROM and its outcome. Int J Reprod Contra Obstet \& Gynecol 2015;4 (5):1422-6.

[24] Rana M, Patra S, Puri M, et al. Foetomaternal outcome in preterm premature rupture of membrane. Int J Infertil foetal Med 2014;5 (1):18-21.

[25] Shukla P, Bhargava M, Disha. Study of maternal and foetal outcome in preterm premature rupture of membrane. Journal of Evolution of Medical and Dental Sciences 2014;3 (7):1789-95.

[26] Okunades KS, Ajepe A, Omisakin SI, et al. A review of foetomaternal outcome of preterm prelabour rupture of membranes in a tertiary hospital in Lagos, South-West Nigeria. Nigerian Hospital Practice 2015;16 (1-3):13-8.

[27] Palve TT, Bhattacharya R. Study of foetomaternal outcome in premature rupture of membranes. Global Journal for Research Analysis 2018;6 (11). 